\title{
The effect of N-nitro-L-arginine and aminoguanidine treatment on changes in constitutive and inducible nitric oxide synthases in the spinal cord after sciatic nerve transection
}

\author{
NADEZDA LUKACOVA ${ }^{1}$, ALEXANDRA DAVIDOVA $^{1}$, DALIBOR KOLESAR $^{1}$, \\ MARIA KOLESAROVA $^{1}$, ANDREA SCHREIBEROVA ${ }^{1}$, MONIKA LACKOVA ${ }^{1}$, \\ OLGA KRIZANOVA $^{2}$, MARTIN MARSALA ${ }^{3}$ and JOZEF MARSALA ${ }^{1}$ \\ ${ }^{1}$ Institute of Neurobiology, Slovak Academy of Sciences, Kosice; ${ }^{2}$ Institute of Molecular Physiology and Genetics, \\ Slovak Academy of Sciences, Bratislava, Slovak Republic; ${ }^{3}$ Anesthesiology Research Laboratory, \\ University of California, San Diego, La Jolla, CA, USA
}

Received November 7, 2007; Accepted December 28, 2007

\begin{abstract}
Ca}^{2+}$-dependent and $\mathrm{Ca}^{2+}$-independent nitric oxide synthase (NOS) activity, and neuronal and inducible NOS immunoreactivity (nNOS-IR and iNOS-IR), were investigated in the rabbit lower lumbar spinal cord after i) sciatic nerve transection and survival of experimental animals for 2 weeks, ii) treatment of animals with N-nitro-L-arginine (NNLA), an inhibitor of nNOS dosed at $20 \mathrm{mg} / \mathrm{b} . \mathrm{w}$. for 12 days, and iii) after treatment of animals with the inducible NOS (iNOS) inhibitor, aminoguanidine, dosed at $100 \mathrm{mg} / \mathrm{b} . \mathrm{w}$. for 4 and 12 days. Our attention was focused on the dorsal part of L4-L6 segments receiving sensory inputs from the sciatic nerve, and on the ventral part consisting of sciatic nerve motor neurons. Sciatic nerve transection increased $\mathrm{Ca}^{2+}$-dependent NOS activity and the density of nNOS in the dorsal part of the spinal cord on the ipsilateral side. NNLA treatment effectively reduced nNOS-IR in both the dorsal horn and the dorsal column, and decreased $\mathrm{Ca}^{2+}$-dependent NOS activity in the lower lumbar segments. Immunocytochemical analysis disclosed the up-regulation of iNOS immunoreactive staining after peripheral axotomy in $\alpha$-motoneurons. The changes in iNOS expression and $\mathrm{Ca}^{2+}$-independent NOS activity were not significantly corrected by aminoguanidine treatment for 4 days. Long-lasting iNOS inhibition decreased $\mathrm{Ca}^{2+}$-independent NOS activity, but caused motor neuron degeneration and mediated small necrotic foci in the ventrolateral portion of
\end{abstract}

Correspondence to: Dr Nadezda Lukacova, Institute of Neurobiology, Slovak Academy of Sciences, Soltésovej 4, 04001 Kosice, Slovak Republic

E-mail: lukacova@saske.sk

Key words: sciatic nerve transection, rabbit, constitutive and inducible nitric oxide synthase, motoneurons, N-nitro-L-arginine, aminoguanidine treatment the ventral horn. The results of the present study provide evidence that constitutive NOS inhibition by NNLA is more effective than specific long-lasting inhibition of iNOS by aminoguanidine treatment.

\section{Introduction}

Although the effect of peripheral axotomy on the nitrergic mechanism has been extensively investigated, the causality of neuronal damage in the spinal cord and the effect of experimental treatment is still considered controversial. Nitric oxide (NO), generated by nitric oxide synthases (NOSs), has a variety of physiological functions. It acts as a messenger molecule regulating blood vessel dilatation and neuronal plasticity $(1,2)$, and serves as a neuromodulator in the processing of nociceptive $(3,4)$ and proprioceptive stimuli $(5,6)$. Constitutive NOS (cNOS), activated by the increase of cytosolic calcium under some pathological conditions, releases relatively low levels of $\mathrm{NO}$ over several minutes (7), while inducible NOS (iNOS) is expressed after the stimulation of immunological or inflammatory reactions and produces large amounts of NO for extended periods of time (8). Under conditions of inappropriate activation, NO may act as a mediator of NMDA receptor-induced toxicity (9-11) providing the substrate for an abrupt formation of peroxynitrite. This process can cause irreversible damage resulting in a decrease or complete loss of neuronal viability. Neuronal and inducible NOS isoform inhibitors are therefore widely used to inhibit NO synthesis, thus controlling the contribution of the effect of NO on the overall response to axotomy and other neuropathies.

Peripheral nerve injury results in a dramatic NOS upregulation in spinal (12) and peripheral (5,6,13-15) neurons, normally devoid of the enzyme, or expressing it at very low levels $(16,17)$. In rabbits (12) and rats (18), sciatic nerve sectioning leads to a marked decrease in the number of small NOS immunoreactive (NOS-IR) neurons in superficial laminae, playing an important role in the sensation of pain (19). Strong up-regulation of NOS expression was detected 
in medium-sized neurons in laminae III and IV (12) and in motoneurons $(16,17)$. This increase in enzyme activity seems to be the result of a loss of contact with post-synaptic targets due to nonpermissible or very poor environments for axonal regeneration (20). Studies performed with the injection of specific neurotrophic factors suggest that brain-derived neurotrophic factor (BDNF) and neutrophin-4/5 (NT-4/5) promote the survival of axotomized retinal ganglion cells (21). Estévez et al (22) suggested the association of NO with the death of motoneurons cultured in the absence of brainderived neurotrophic factor. Furthermore, the effective alleviation of neuronal loss was noted after spinal root avulsion in adult rats treated with neurotrophic factors. This effect was associated with the inhibition of neuronal NOS (nNOS) expression (23). In contrast, recent experiments performed with targeted disruption of genes in mice have shown that nNOS is necessary for the maintenance of spinal motoneurons $(24,25)$.

In the present study we examined the effect of the cNOS inhibitor N-nitro-L-arginine (NNLA) and the iNOS inhibitor aminoguanidine on changes in NOS pools in a model of unilateral sciatic nerve transection, with the aim of detecting the relative contribution of both inhibitors to NO production and to neuronal damage after peripheral axotomy. Our attention was focused on the dorsal part of the lower lumbar spinal cord, receiving sensory inputs from the sciatic nerve through sensitive neurons localized in respective dorsal root ganglia, and on motor neurons of the sciatic nerve located in the ventral horn of L4-L6 segments. The lower lumbar (L4L6) spinal cord was processed for immunocytochemical detection of neuronal and inducible NOS immunoreactivity, both quantified by densitometric analysis. Radioassay detection was used to determine $\mathrm{Ca}^{2+}$-dependent and $\mathrm{Ca}^{2+}$ independent NOS activity.

\section{Materials and methods}

Surgical procedure. Forty rabbits of both sexes weighing 2.5-3.5 kg were anesthetized with a mixture of ketamine and xylazine (100 mg/kg and $15 \mathrm{mg} / \mathrm{kg}$ b.w., i.m.) and artificially ventilated in a respirator with oxygen and nitrous oxide (Anemat N8 Chirana, Czech Republic). Experimental protocols were approved by the Institute of Neurobiology Animal Care Committee. All experiments conformed to the National Institutes of Health Guide for the Care and Use of Laboratory Animals. Peripheral neuropathy was induced by right sciatic nerve transection in the middle third of the thigh. The distal and the proximal parts of the exposed sciatic nerve were ligated and afterwards the sciatic nerve was transected. Experimental animals survived for 14 days.

Treatment with NOS inhibitors. In one group of experiments the rabbits $(n=8)$ were treated with NNLA, an inhibitor of the neuronal isoform of NOS, dosed at $20 \mathrm{mg} / \mathrm{b} . w$. NNLA was administered intraperitoneally once a day for 12 days. Control animals $(n=8)$ received an equal volume of vehicle. In the other group the animals $(n=16)$ received intraperitoneal injections of aminoguanidine, inhibiting the inducible isoform of NOS or its vehicle $(n=8)$ one day after the right sciatic nerve transection. The drug was administered twice a day at a dose of $100 \mathrm{mg} / \mathrm{kg}$ b.w. for 4 and 12 days. Nontreated animals subjected to spinal cord transection were used for comparison.

Sample dissection for biochemical analyses. Two weeks following axotomy, rabbits were re-anesthetized. The backbone (segments L4-L6) was excised, the spinal cord was quickly extruded into ice-cold isotonic saline, cleaned from envelopes and carefully frozen in liquid nitrogen. The right side of the removed spinal cord was marked with a felt-tip pen to identify the right (ipsilateral) and left (contralateral) sides. For measurement of $\mathrm{Ca}^{2+}$-dependent NOS activity, L4-L6 segments were divided into the dorsal horn and dorsal column. Dorsal and ventral parts of these segments were processed for inducible NOS activity. All samples taken from the right and left halves of the L4-L6 segments were assayed separately.

Nitric oxide synthase radioassay. Both $\mathrm{Ca}^{2+}$-dependent and $\mathrm{Ca}^{2+}$-independent NOS activity were determined by the conversion of $\mathrm{L}^{-}\left[{ }^{14} \mathrm{C}\right]$ arginine to $\mathrm{L}^{-}\left[{ }^{14} \mathrm{C}\right]$ citrulline according to the method of Bredt and Snyder (26), with a slight modification by Strosznajder and Chalimoniuk (27). Frozen spinal cord samples were homogenized in 100-150 $\mu \mathrm{l}$ of ice-cold Tris-HCl buffer (10 mM, pH 7.4) containing $1 \mathrm{mM}$ EDTA and protease inhibitor cocktail. Aliquots of the homogenate $(200 \mu \mathrm{g} / \mathrm{ml})$ were incubated for $45 \mathrm{~min}\left(37^{\circ} \mathrm{C}\right)$ with $10 \mu \mathrm{M}$ ${ }_{\mathrm{L}}-\left[{ }^{14} \mathrm{C}\right] \operatorname{arginine}(1 \mu \mathrm{Ci}), 1 \mathrm{mM}$ NADPH, $1 \mu \mathrm{M}$ calmodulin in a $50 \mathrm{mM}$ HEPES buffer (pH 7.4) containing $1 \mathrm{mM}$ dithiothreitol (DTT), $1 \mathrm{mM}$ ethylenediaminetetraacetic acid (EDTA), $100 \mu \mathrm{M}$ flavin mononucleotide (FMN), $100 \mu \mathrm{M}$ flavin adenine dinucleotide (FAD), $2 \mathrm{mM} \mathrm{CaCl}_{2}$, and $15 \mu \mathrm{M}$ tetrahydrobiopterin $\left(\mathrm{H}_{4} \mathrm{~B}\right)$, in a final volume of $300 \mu 1$. iNOS activity was evaluated in the absence of $\mathrm{CaCl}_{2}$ in the mixture medium. The reaction was stopped by the addition of $1 \mathrm{ml}$ of ice-cold $100 \mathrm{mM}$ HEPES buffer ( $\mathrm{pH}$ 5.5) containing $10 \mathrm{mM}$ EDTA. Samples were applied to a Dowex AG 50W-X8 cationic-exchange column $\left(\mathrm{Na}^{+}\right.$form) in order to remove the $\mathrm{L}^{-}\left[{ }^{14} \mathrm{C}\right]$ arginine. The columns were washed with $2 \mathrm{ml}$ of deionized water to elute the ${ }_{\mathrm{L}}-\left[{ }^{14} \mathrm{C}\right]$ citrulline. Samples were centrifuged at $1000 \mathrm{x} \mathrm{g}$ for $5 \mathrm{~min}$ and aliquots $(0.5 \mathrm{ml})$ of supernatant fractions were mixed with $5 \mathrm{ml}$ of Bray's fluid into scintillation vials and then counted in a Beckman LS-3801 spectrometer. Cpms were converted to dpms using $\left[{ }^{14} \mathrm{C}\right]-$ quenched standards. Levels of $\left[{ }^{14} \mathrm{C}\right]$ citrulline were computed after subtracting the blank which represented nonspecific radioactivity in the absence of enzyme activity. Protein determination was performed using a Bradford assay (28). The results from the analyses were expressed as $\mathrm{pmol} / \mathrm{mg}$ protein.

NOS immunohistochemistry. Fourteen days after unilateral sciatic nerve transection, the animals were deeply anesthetized with thiopental $(50 \mathrm{mg} / \mathrm{kg}$, i.v.), perfused intracardially with heparinized saline and subsequently with freshly prepared $4 \%$ paraformaldehyde in $0.1 \mathrm{M}$ phosphatebuffered saline (PBS; pH 7.4, Sigma). The spinal cord from each animal was removed and post-fixed in the same fixative for $24 \mathrm{~h}$, then dissected into L4-L6 segments and cryoprotected in PBS containing sucrose $(30 \%)$. One day 

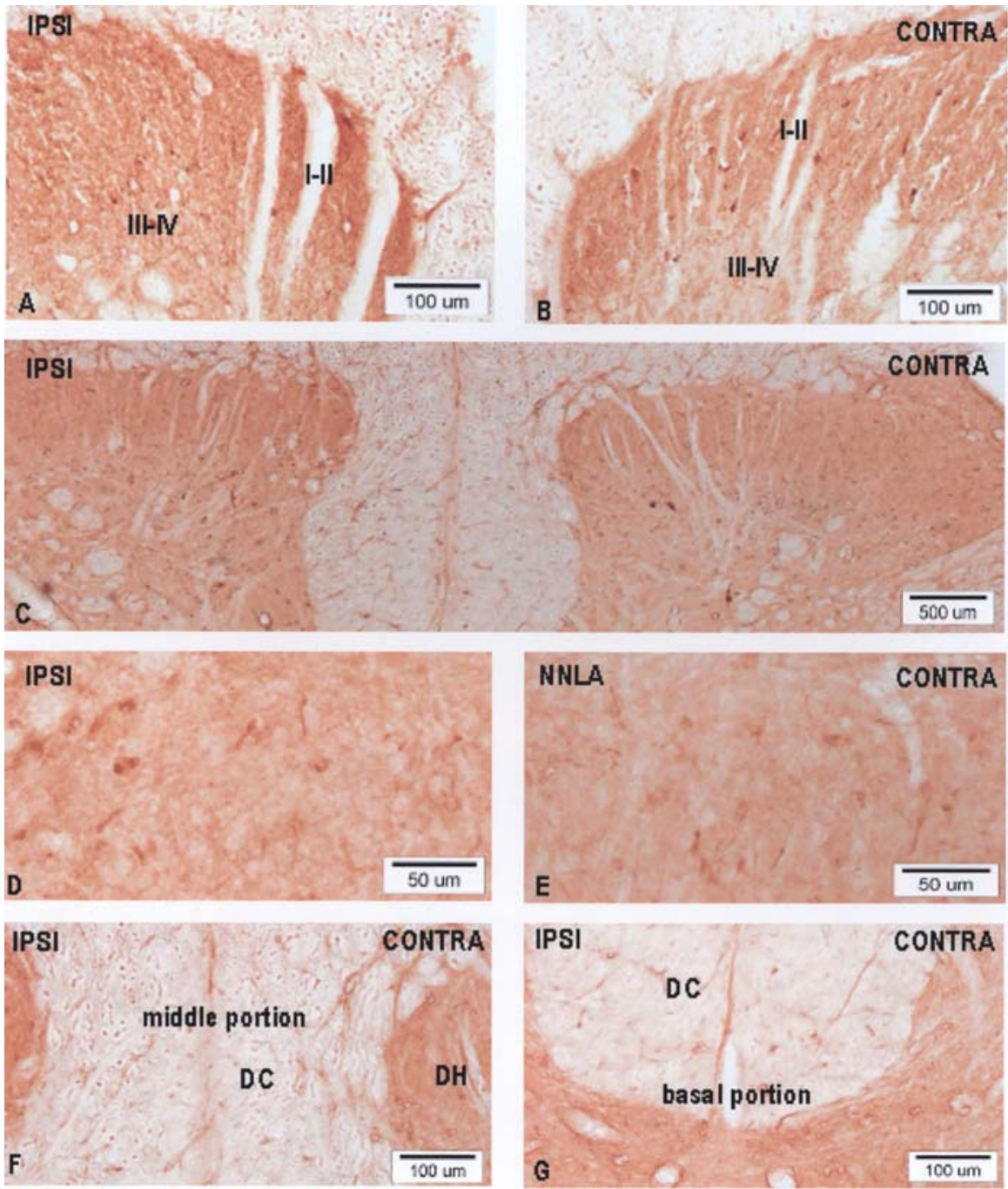

Figure 1. Representative light microphotographs showing neuronal nitric oxide synthase immunoreactivity (nNOS-IR) in the dorsal horn (A-E) and dorsal column (A, B, F and G) of L5 segment two weeks after unilateral sciatic nerve transection (A and B), and after N-nitro-L-arginine (NNLA) treatment for 12 days $(\mathrm{C}$ and $\mathrm{G})$. Transverse sections cut at the L5 level show the density of nNOS-IR in laminae I-IV on the ipsilateral (A) and contralateral (B) side of the dorsal horn and in axons located around the dorsomedial part of the dorsal horn. Microphotographs (D and E) depict boxed areas in C. High density of nNOS immunoreactive neuropil was noted in the medial part of laminae I and II on the ipsilateral side (A). On the same side, clear enhancement of nNOS-IR was seen in a group of axons located dorsomedially to the dorsal horn. Note the lower density of nNOS-IR staining in the neuropil of superficial layers of the dorsal horn after NNLA treatment (C and D). The intensity of nNOS-IR was reduced in the middle portion of the dorsal column after NNLA (F). In the basal portion we noted complete loss of nNOS immunoreactive axons on both sides of the injury (G). ipsi, ipsilateral; contra, contralateral.

later 30 serial sections ( $40 \mu \mathrm{m}$ thick) were cut with a freezing microtome from each segment studied. Spinal cord sections taken from animals subjected to sciatic nerve transection and NNLA treatment were processed for nNOS immunohistochemistry, while whose taken from animals with sciatic nerve transection and aminoguanidine treatment were processed for iNOS immunohistochemistry. Free-floating tissue sections were pre-treated with $0.3 \% \mathrm{H}_{2} \mathrm{O}_{2}$ in PBS for $30 \mathrm{~min}$, then washed and blocked with $10 \%$ normal goat serum (Vector Laboratories, Burlington, CA, Product no. $\mathrm{Q} 0407)$ for $2 \mathrm{~h}$. The spinal cord sections used for nNOS-IR processing were incubated in polyclonal sheep-nNOSantiserum, 1:500 and for determination of iNOS-IR in polyclonal rabbit-iNOS-antiserum (Sigma), 1:3000 dilution with $0.3 \%$ Triton X-100 in PBS overnight at $4{ }^{\circ} \mathrm{C}$ with gentle agitation. After several washes in PBS, the sections were incubated with biotinylated anti-sheep and anti-rabbit secondary antibody 1:200 (Vector Laboratories) for $2 \mathrm{~h}$, rinsed in PBS and reacted with avidin biotin reagents 1:100 for $1 \mathrm{~h}$ at room temperature. After three washes in PBS, the sections were developed in diaminobenzidine-tetrahydrochloride (DAB) solution containing $\mathrm{H}_{2} \mathrm{O}_{2}$ in PBS for 2$4 \mathrm{~min}$. The sections were washed in distilled water, mounted on Colorfrost/Plus Microscope slides (Fisher Scientific, USA), air-dried and dehydrated with graded alcohol (50$100 \%$ ) followed by xylene and coverslipped with Entellan. On a few sections the primary nNOS and iNOS antibodies were omitted from the staining procedures, so that no nNOS and iNOS positive cell bodies and axons were detected.

Densitometric analysis. Densitometric analysis of iNOS immunoreactivity (iNOS-IR) was performed on a PC using the UTHSCSA Image Tool program enabling the reliable detection of subtle differences in the ventrolateral portion of 

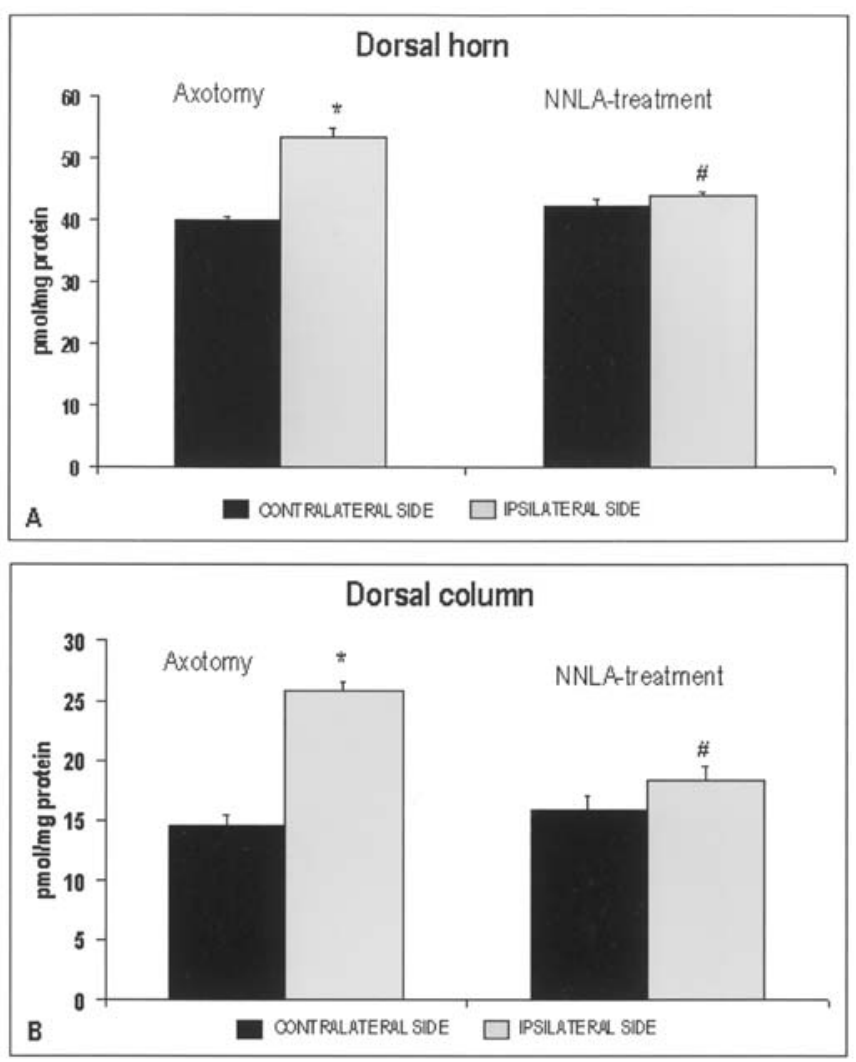

Figure 2. Constitutive nitric oxide synthase (cNOS) activity in the dorsal horn (A) and dorsal column (B) of L4-L6 segments two weeks after unilateral sciatic nerve transection and N-nitro-L-arginine (NNLA) treatment for 12 days. The results are expressed as pmol/mg protein. Data are given as means $\pm \operatorname{SEM}(n=5) ;{ }^{*} \mathrm{p}<0.05$ with respect to the contralateral side; ${ }^{\mathrm{p}}<0.05$ with respect to axotomy without treatment.

the ventral horn and in $\alpha$-motoneurons of L4-L6 segments. The areas of interest were outlined by the operator and then the program calculated the average optical density of the pixels contained within the boundaries of each outlined area using a 256-unit gray scale (0, black; 256, white). The optical density of iNOS-IR staining is displayed as a twodimensional densitogram. The value along the vertical y-axis gives the relative number of pixels as the smallest elements of a image that can be individually displayed, ranging in values from 0 to 256. Densitometric patterns resulting from iNOS immunocytochemical processing of spinal cord sections may display a variety of appearances depending on the site and intensity of iNOS staining, e.g. intensely stained somata are monitored as large, highly characteristic black areas commonly located close to value zero or in the left third of the densitogram on the horizontal $\mathrm{x}$-axis, displaying variable height of the spikes depending on the extent of dark or dark-brown areas under study. The high-discrimination performance of the UTHSCSA Image Tool program allows measurement of the background optical density occurring in a given area.

Statistical analysis. The results of $\mathrm{Ca}^{2+}$-dependent and iNOS activities were statistically evaluated using ANOVA as well as the Tukey-Kramer test, and are presented as the means \pm SEM.

\section{Results}

nNOS-IR and $\mathrm{Ca}^{2+}$-dependent NOS activity in the dorsal horn and dorsal column of L4-L6 segments after unilateral sciatic nerve transection and NNLA treatment. Our previous study revealed a marked increase in $\mathrm{Ca}^{2+}$-dependent NOS activity in the dorsal horn (125\%) and dorsal column (177\%) after sciatic nerve transection. Simultaneously, the number of nNOS-IR neurons was significantly modified in the dorsal horn (12). In the present study we performed immunohistochemistry to examine the expression of nNOS-IR, and radioassay detection for the determination of $\mathrm{Ca}^{2+}$-dependent NOS activity in the dorsal part of the L4-L6 segments after unilateral sciatic nerve transection and NNLA treatment. Two weeks after peripheral axotomy, nNOS-IR was distributed almost homogeneously in both medial and lateral parts of the superficial dorsal horn on the contralateral side. We noted normal staining in laminae I and II and quite weak staining in laminae III and IV (Fig. 1B). Increased density of fiber-like and punctate non-somatic nNOS staining was found mostly in the medial part of laminae I-IV on the ipsilateral side of the sciatic nerve transection (Fig. 1A). In the white matter, peripheral axotomy caused increased density of axonal nNOS staining in the ipsilateral dorsal column. Clear enhancement of nNOS-IR was visible around the dorsomedial part of the dorsal horn (Fig. 1A). On the contralateral side, nNOS immunoreactive axons were distributed only randomly (Fig. 1B).

After NNLA treatment, both nNOS-IR and calciumdependent NOS activity were substantially reduced in the dorsal horn (Figs. 1C-E, and 2A). However, we did not observe significant differences between the contralateral and ipsilateral sides in the density of immunocytochemical detection of nNOS, or in calcium-dependent NOS activity assessed by radioassay. NNLA treatment reduced the nNOSimmunoreactivity in the middle portion of the dorsal column (Fig. 1F). In the basal portion we noted a complete loss of nNOS-IR axons on both sides of the injury (Fig. 1G). These findings were accompanied by a significant decrease in enzyme activity in the dorsal column on the ipsilateral side (Fig. 2B).

Our results showed that two weeks after unilateral sciatic nerve transection, the expression of nNOS increased in the dorsal part of the spinal cord on the ipsilateral side, and that treatment with the nNOS inhibitor NNLA dosed at 20 $\mathrm{mg} / \mathrm{b} . \mathrm{w}$. for 12 days effectively reduced the neuronal isoform of NOS in the dorsal horn and in the dorsal column of lower lumbar segments.

The effect of aminoguanidine on changes in iNOS-IR and $\mathrm{Ca}^{2+}$-independent NOS activity in the dorsal and ventral parts of L4-L6 segments after sciatic nerve transection. After peripheral axotomy and 14 days of survival the density of iNOS-IR was up-regulated in large $\alpha$-motoneurons and in their primary dendrites on the side of the injury (Fig. 3D and E). The densitograms of outlined iNOS-IR $\alpha$-motoneurons show the optical density with black at zero and white at 256 

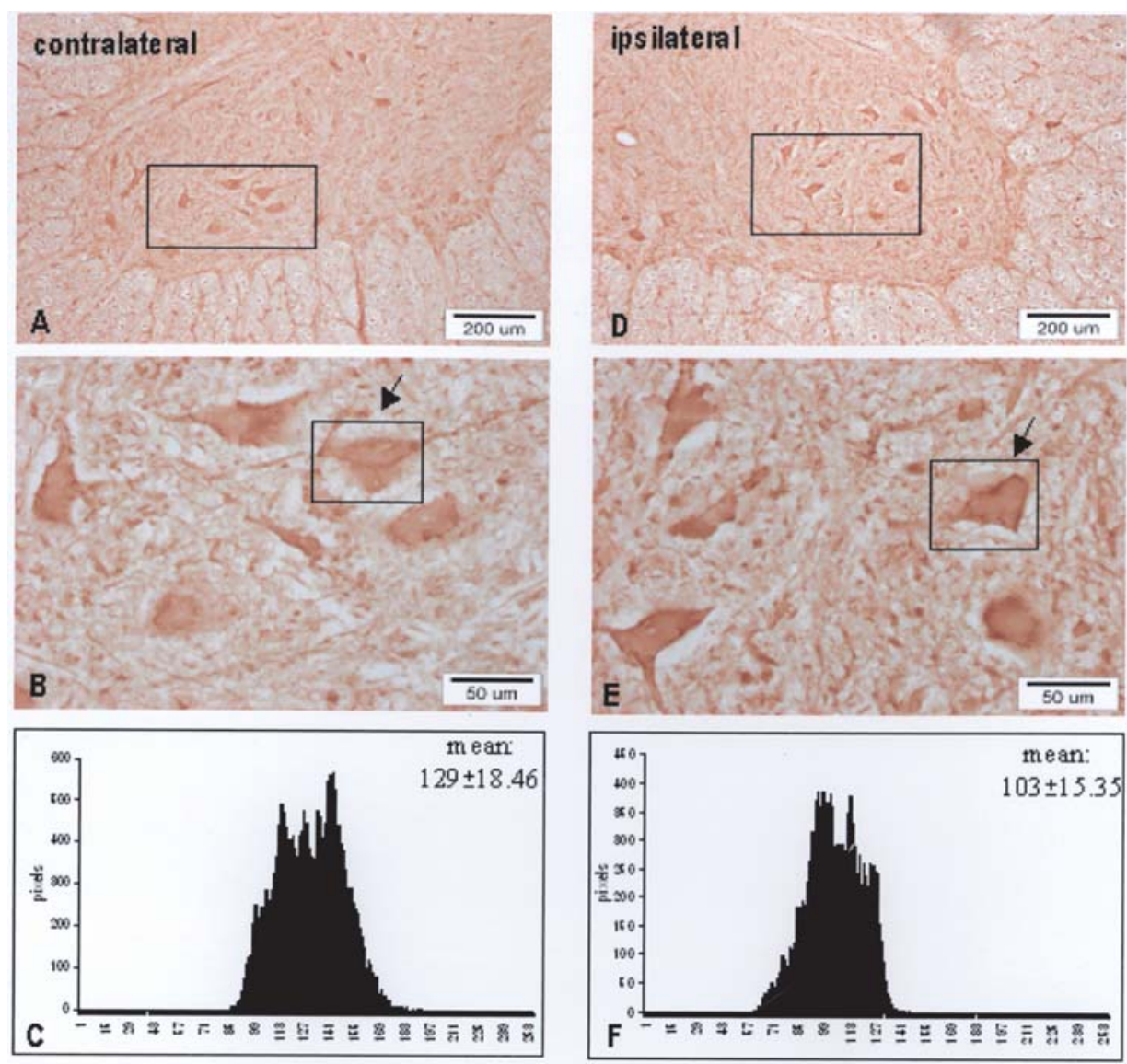

Figure 3. Microphotographs (A, B, D and E) and densitograms (C and F) showing inducible nitric oxide synthase immunoreactivity (iNOS-IR) in the ventral horn of the L6 segment on both contralateral $(\mathrm{A}, \mathrm{B}, \mathrm{C})$ and ipsilateral $(\mathrm{D}, \mathrm{E}$ and $\mathrm{F})$ sides of the spinal cord of animals subjected to sciatic nerve transection and survival for 14 days. Transverse sections cut at the L6 level depict the location of iNOS-immunoreactive (IR) $\alpha$-motoneurons on contralateral (A) and ipsilateral (D) sides. Microphotographs (B and E) depict boxed areas in A and D. Higher density of iNOS-IR is seen in $\alpha-$ motoneurons on the ipsilateral side (E). Densitograms $(\mathrm{C}$ and $\mathrm{F})$ show the density of the outlined $\alpha$-motoneurons in B and E. Lower density of iNOS-IR staining (129 \pm 18.46$)$ is seen in $\alpha$-motoneurons on the contralateral side (C).

on the gray scale (Fig. 3C and F). Considering the location of the densitograms on the gray scale, the intensity of iNOS-IR seems to be lower on the contralateral side, and it appears that $\alpha$-motoneurons are more intensely stained on the ipsilateral side. When the enzyme activity was measured by radioassay detection, a marked increase in iNOS activity was noted on the side of the injury in both the dorsal and ventral parts of L4-L6 segments (Fig. 4).

When experimental animals were treated with aminoguanidine for 4 days, the distribution density of the immunohistochemical reaction was very heterogeneous. On the side of the injury, increased iNOS positivity was found in a group of $\alpha$-motoneurons along with axons located not only inside the ventral horn, but also passing through the ventral column (Fig. 5A and B). An unexpected finding was the occurrence of bouton-like iNOS-IR structures (ranging between 5 and $12-14 \mu \mathrm{m}$ ), often closely opposing $\alpha$-motoneurons. The most significant sign of iNOS-immunopositivity was quite dark immunostaining of the intragriseal portion of iNOS-IR axons before they leave the ventral horn and enter the white matter columns. Some $\alpha$-motoneurons were without iNOS-IR. The treatment of animals with aminoguanidine, dosed at $100 \mathrm{mg} / \mathrm{b} . \mathrm{w}$. for 4 days did not noticeably influence iNOS activity in the dorsal and ventral parts of L4-L6 segments
(Fig. 4). Enzyme activity decreased significantly in the group of animals treated with aminoguanidine for 12 days. In the ventral part, iNOS activity decreased below the control value (Fig. 4). Two critical signs were noted in the ventral horn of L5-L6 segments after treatment of animals with aminoguanidine for 12 days (Fig. 6). On both sides, irrespective of axotomy, iNOS immunolabelling was significantly suppressed and, more importantly, on the operated side, small necrotic, sometimes confluent foci were identified in the ventrolateral portion of the ventral horn. No $\alpha$-motoneurons could be identified in the ventrolateral ventral horn. However, the core of the ventral horn and intermediate zone were free of necrotic foci.

\section{Discussion}

Using radioassay and immunocytochemistry we demonstrated that unilateral sciatic nerve transection increased $\mathrm{Ca}^{2+}$-dependent NOS activity and the expression of nNOS in the ipsilateral dorsal part of lower lumbar spinal cord segments, and that the treatment of animals with NNLA dosed at $20 \mathrm{mg} / \mathrm{b} . \mathrm{w}$. for 12 days effectively reduced both the enzyme activity and the nNOS-IR in the ipsilateral dorsal horn and dorsal column. We did not observe differences in 


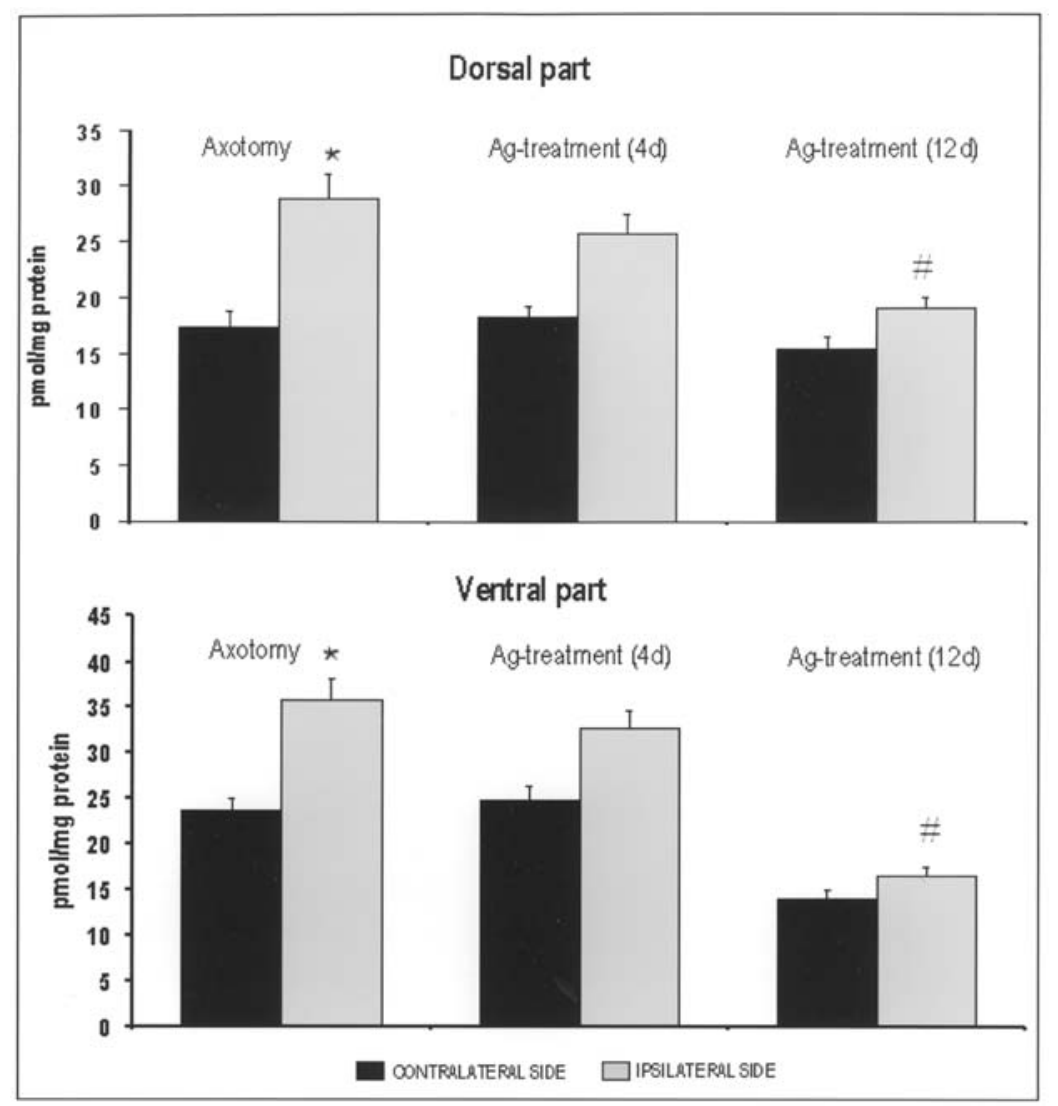

Figure 4. Inducible nitric oxide synthase (iNOS) activity in the dorsal (A) and ventral (B) part of L4-L6 segments after sciatic nerve transection and treatment of animals with aminoguanidine (Ag) for 4 and 12 days. Experimental animals survived for 14 days. The results are expressed as pmol/mg protein. Data are given as means $\pm \operatorname{SEM}(\mathrm{n}=5) ;{ }^{*} \mathrm{p}<0.05$ with respect to the contralateral side; ${ }^{*} \mathrm{p}<0.05$ with respect to axotomy without treatment.

the density of nNOS immunostaining of lower lumbar motoneurons on contralateral and ipsilateral sides after peripheral axotomy, nor after NNLA treatment. Immunocytochemical analysis disclosed up-regulation of iNOS-IR staining after peripheral axotomy in $\alpha$-motoneurons localized in the ventrolateral part of the ipsilateral ventral horn. The changes in iNOS activity and iNOS expression were not corrected by aminoguanidine treatment for 4 days. However, the iNOS-IR and $\mathrm{Ca}^{2+}$-independent enzyme activity decreased significantly in $\alpha$-motoneurons when the animals were treated with aminoguanidine for 12 days.

The participation of NO in abnormal neural activity and pain behaviour (3) has been indicated previously. However, the role of $\mathrm{NO}$ and/or some neuropeptides that might modulate spinal microcircuits (29-35) is not clearly defined. The enhancement of $\mathrm{Ca}^{2+}$-dependent NOS activity found after nerve injury in the ipsilateral dorsal part of the spinal cord seems to be associated with an increase in total NOS activity (36) and nNOS-IR in the DRG corresponding to the ipsilateral spinal nerve $(5,6,12-15,18)$. This finding is also consistent with previously reported ipsilateral increase in the number of nNOS-immunopositive fibers in laminae I and II, and higher nNOS-IR in large multipolar cell profiles in laminae III and IV in L4-L6 segments (12). In addition, the present data clearly show unilateral enhancement of nNOS-IR in thick primary myelinated $A B$ dorsal root afferents passing near the dorsomedial border of the dorsal horn within the dorsal funiculus and entering the gray matter underneath the substantia gelatinosa. There was no evidence of higher nNOS expression in axotomized $\alpha$-motoneurons, nor of more numerous nNOS-IR neurons on the injured side two weeks after axotomy, although the counting of immunolabelled $\alpha$-motoneurons was not attempted. These results are in agreement with previous reports showing that motoneurons remained unstained or weakly stained for nNOS after peripheral transections/ligations at all times studied $(15,18,25,37)$. It is generally believed that interruption of the axonal transport of neurotrophic factors from the periphery to the cell bodies plays a key role in the degenerative reaction of motor neurons and DRG cells $(38,39)$. Terenghi $(40)$ reported that axotomized motoneurons may receive neurotrophic factors from Schwann cells surrounding the peripheral axons. The Schwann cells and macrophages provide support for removing myelin debris and releasing growth factors and adhesion molecules required in regeneration (15,40-44). Such peripheral support may help motoneurons to survive longer after axotomy, long enough to allow the induction of the Mn isoform of SOD (superoxide dismutase), which would counteract the oxidative stress induced by peripheral axotomy (45).

Since there is evidence that the viability of axotomized neurons can be enhanced by inhibitors of nitric oxide synthesis (46-48), several approaches were used to determine which isoform of NOS may be implicated in the enhancement of NO production after nerve injuries. Keilhoff et al (25) demonstrated that the profiles of degenerated interneurons in laminae I and II, and partly motor neurons, 

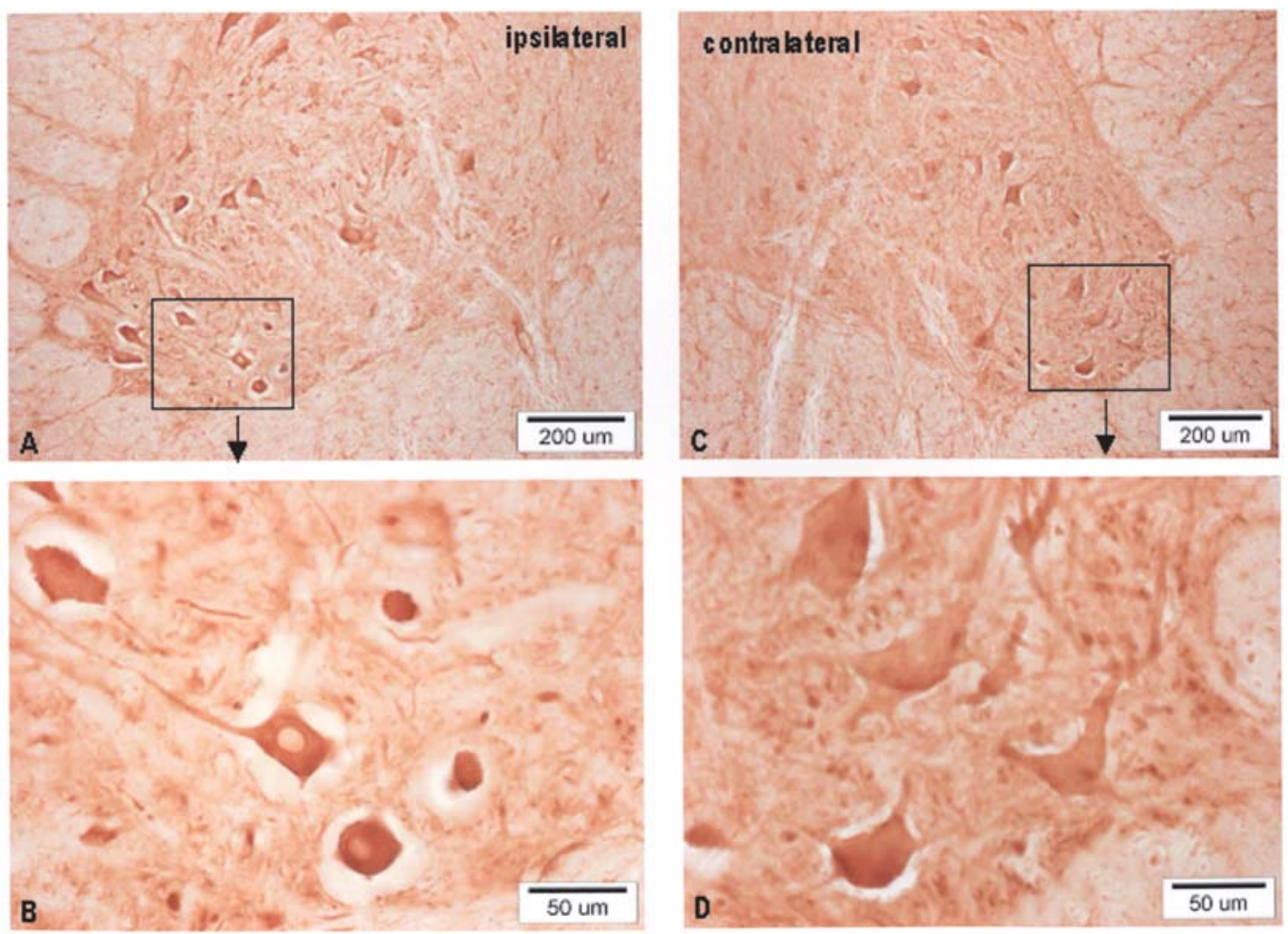

Figure 5. Microphotographs showing inducible nitric oxide synthase immunoreactivity (iNOS-IR) in the ventral horn of the L6 segment on both ipsilateral (A and B) and contralateral (C and D) sides of the spinal cord two weeks after unilateral sciatic nerve transection and after treatment of animals with aminoguanidine for 4 days. Microphotographs (B and D) depict boxed areas in A and C. Higher iNOS immunoreactivity is seen in a group of $\alpha$-motoneurons on the ipsilateral side (B).

\section{Contrakateral side}
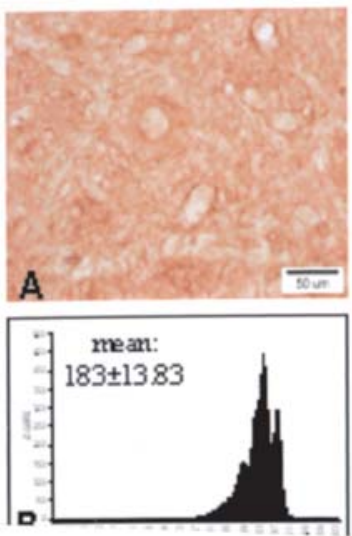

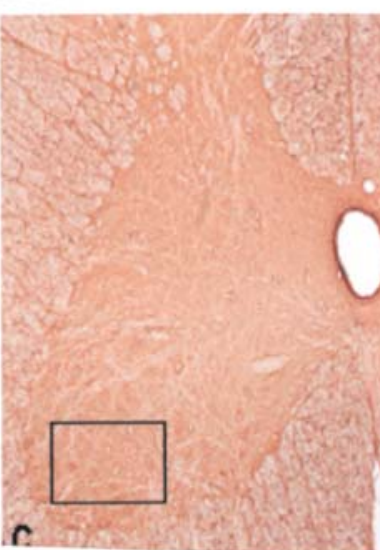

Ipsilate ral side
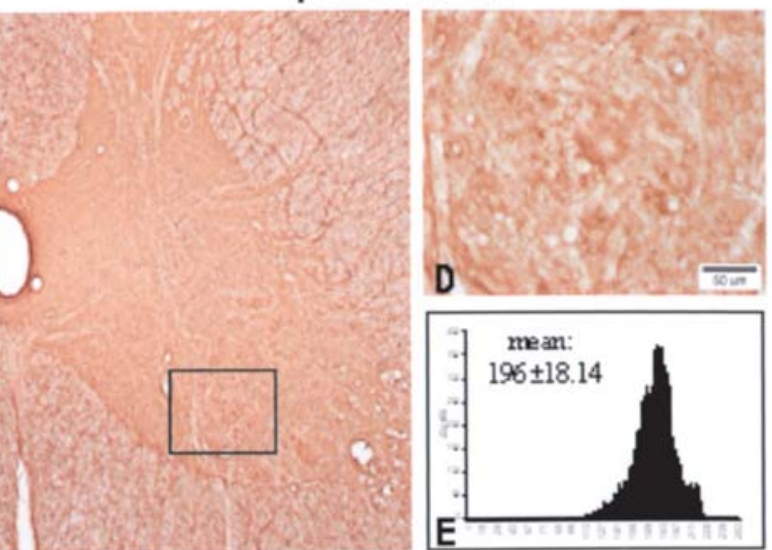

Figure 6. Microphotographs (A, C and D) and densitograms (B and E) showing inducible nitric oxide synthase immunoreactivity (iNOS-IR) in the ventral horn of L6 segment on both contralateral (A, B and C-left side) and ipsilateral (C-right side, D and E) sides of the spinal cord two weeks after unilateral sciatic nerve transection and treatment of animals with aminoguanidine for 12 days. Microphotographs (A and D) depict boxed areas in C. Note suppressed iNOS-IR on both sides of the ventral horn. No $\alpha$-motoneurons were identified in the ventrolateral portion of the ventral horn.

were more prominent in nNOS-KO mice 6 weeks after axotomy than in iNOS-KO mice. Watabe and co-workers (49) demonstrated that the severity of neuronal loss after peripheral lesion can be alleviated by blocking nNOS expression, and $\mathrm{Wu}$ and $\mathrm{Li}$ (50) reported the prevention of motoneuron death by the alteration of nNOS expression following spinal root avulsion. Martin et al (51) examined motor neuron survival in mice with different NOS genotypes at 7,14 or 21 days after unilateral sciatic nerve avulsion, and reported that knock-out of nNOS and iNOS protected motor neurons against apoptosis at 21 days, but mice deficient in eNOS were not protected. In our experimental model, iNOS-IR was reduced in ipsilateral motor neurons compared with control contralateral motoneurons in the rat lumbar spinal cord at 5 days after nerve avulsion. Our results suggest that repeated injections of $\mathrm{Ca}^{2+}$-dependent NOS inhibitor 
dosed at $20 \mathrm{mg} / \mathrm{b} . \mathrm{w}$. were effective in decreasing both the enzyme activity and the density of nNOS immunostaining in the dorsal and ventral parts of the spinal cord. iNOS, typically induced by cytokines and endotoxins, is thought to represent a physiological response of the immune system to tissue damage (52). The treatment of animals with the iNOS inhibitor aminoguanidine, dosed at $100 \mathrm{mg} / \mathrm{b} . \mathrm{w}$. for 4 days did not decrease iNOS immunolabelling, nor did it influence neuronal survival. This finding was unexpected considering that iNOS expression is believed to be responsible for the majority of post-traumatic NO-mediated neuronal death in the central nervous system (53). We detected clear iNOS immunolabelling in $\alpha$-motoneurons including fibers in laminae VII and VIII. Occasionally some $\alpha$-motoneurons responding with high iNOS-IR were seen in a juxtagriseal position on the injured side. The occurrence of a pericellular halo was noted on some sections occurring around large $\alpha$-motoneurons. We suppose that this was a result of immunohistochemical processing as this is commonly seen in neurons found in the first phase of retrograde reaction (edema). In the group of animals treated with aminoguanidine for 12 days we noted marked decrease in $\mathrm{Ca}^{2+}$ independent NOS activity on the side of the injury. The suppression of NO formation by the iNOS inhibitor for a longer period induced degeneration of $\alpha$-motoneurons and created small necrotic foci in the ventrolateral portion of the ventral horn. These results suggest that NO produced by iNOS may regulate the death of axotomized motor neurons in a time-dependent manner. It seems possible that the formation of NO by cNOS early after injury, and by its increased formation via iNOS later on in the affected spinal cord regions, may accelerate neurodestructive events and lead to nitrosylation of proteins, binding to the hem or iron sulfur sites of regulatory proteins (54), as well as to DNA damage and the formation of peroxynitrites (51).

Although NO synthesized by both cNOS and iNOS is toxic to axotomized neurons, cNOS inhibition by NNLA seems to be more neuroprotective than the specific longlasting inhibition of iNOS by aminoguanidine treatment. The results of the present study provide evidence of an important role of nitric oxide contributing to peripheral nerve axotomy death following injury. Since a strong blockade of iNOS activity markedly contributed to the damage of motor neurons at later stages, the mechanism of such regulation should be clarified by taking into consideration apoptotic proteins and/or the formation of peroxynitrite.

\section{Acknowledgements}

The authors thank Mrs. M. Synekova, Mrs. A. Kosova and Mr. D. Krokavec for their excellent technical assistance. This experimental work was supported by VEGA Grants No. 2/5134/25 and 2/0015/08 from the SAS and partly by APVT 51-013002, APVV 0314-06 and CEKVY 2007.

\section{References}

1. Snyder SH: Nitric oxide: first in a new class of neurotransmitters. Science 257: 494-496, 1992.

2. Bohme GA, Bon C, Stutzmann JM, Doble A and Blanchard JC: Possible involvement of nitric oxide in long-term potentiation. Eur J Pharmacol 199: 379-381, 1991.
3. Meller ST, Pechman PS, Gebhart GF and Maves TJ: Nitric oxide mediates the thermal hyperalgesia produced in a model of neuropathic pain in the rat. Neuroscience 50: 7-10, 1992.

4. Levy D, Tal M, Hoke A and Zochodne DW: Transient action of the endothelial constitutive nitric oxide synthase (ecNOS) mediates the development of thermal hypersensitivity following peripheral nerve injury. Eur J Neurosci 12: 2323-2332, 2000.

5. Marsala J, Lukacova N, Sulla I, Wohlfahrt P and Marsala M: The evidence for nitric oxide synthase immunopositivity in the monosynaptic Ia-motoneuron pathway of the dog. Exp Neurol 195: 161-178, 2005.

6. Marsala J, Lukacova N, Kolesar D, Kucharova K and Marsala M: Nitrergic proprioceptive afferents originating from quadriceps femoris muscle are related to monosynaptic Ia-motoneuron stretch reflex circuit in the dog. Cell Mol Neurobiol 26: 1387-1412, 2006.

7. Mayer B, John M, Heinzel B, Werner ER, Wachter H, Schultz G and Bohme E: Brain nitric oxide synthase is a biopterin- and flavin-containing multi-functional oxido-reductase. FEBS Lett 288: 187-191, 1991 .

8. Moncada S, Palmer RM and Higgs EA: Nitric oxide: physiology, pathophysiology, and pharmacology. Pharmacol Rev 43: 109-142, 1991.

9. Dawson TM and Snyder SH: Gases as biological messengers: nitric oxide and carbon monoxide in the brain. J Neurosci 14: 5147-5159, 1994.

10. Strosznajder J, Chalimoniuk M, Samochocki M and Gadamski R: Nitric oxide: a potent mediator of glutamatergic neurotoxicity in brain ischemia. Ann NY Acad Sci 723: 429-432, 1994.

11. Prast $H$ and Philippu A: Nitric oxide as modulator of neuronal function. Prog Neurobiol 64: 51-68, 2001.

12. Lukacova N, Cizkova D, Krizanova O, Pavel J, Marsala M and Marsala J: Peripheral axotomy affects nicotinamide adenine dinucleotide phosphate diaphorase and nitric oxide synthases in the spinal cord of the rabbit. J Neurosci Res 71: 300-313, 2003.

13. Verge VM, Xu Z, Xu XJ, Wiesenfeld-Hallin Z and Hökfelt T: Marked increase in nitric oxide synthase mRNA in rat dorsal root ganglia after peripheral axotomy: in situ hybridization and functional studies. Proc Natl Acad Sci USA 89: 11617-11621, 1992.

14. Shi TJ, Holmberg K, Xu ZQ, Steinbusch H, de Vente J and Hokfelt T: Effect of peripheral nerve injury on cGMP and nitric oxide synthase levels in rat dorsal root ganglia: time course and coexistence. Pain 78: 171-180, 1998.

15. Gonzalez-Hernandez $\mathrm{T}$ and Rustioni A: Expression of three forms of nitric oxide synthase in peripheral nerve regeneration. J Neurosci Res 55: 198-207, 1999.

16. Saito S, Kidd GJ, Trapp BD, Dawson TM, Bredt DS, Wilson DA, Traystman RJ, Snyder SH and Hanley DF: Rat spinal cord neurons contain nitric oxide synthase. Neuroscience 59: 447-456, 1994.

17. Liu Z and Martin LJ: Motor neurons rapidly accumulate DNA single-strand breaks after in vitro exposure to nitric oxide and peroxynitrite and in vivo axotomy. J Comp Neurol 432: 35-60, 2001.

18. Fiallos-Estrada CE, Kummer W, Mayer B, Bravo R, Zimmermann $\mathbf{M}$ and Herdegen T: Long-lasting increase of nitric oxide synthase immunoreactivity, NADPH-diaphorase reaction and c-JUN co-expression in rat dorsal root ganglion neurons following sciatic nerve transection. Neurosci Lett 150: 169-173, 1993.

19. Tessler A, Himes BT, Krieger NR, Murray M and Goldberger ME: Sciatic nerve transection produces death of dorsal root ganglion cells and reversible loss of substance $\mathrm{P}$ in spinal cord. Brain Res 332: 209-218, 1985 .

20. Yu WH: Regulation of nitric oxide synthase expression in motoneurons following nerve injury. Dev Neurosci 19: 247-254, 1997.

21. Peinado-Ramón P, Salvador M, Villegas-Pérez MP and Vidal-Sanz M: Effects of axotomy and intraocular administration of NT-4, NT-3, and brain-derived neurotrophic factor on the survival of adult rat retinal ganglion cells. A quantitative in vivo study. Invest Ophthalmol Vis Sci 37: 489-500, 1996.

22. Estévez AG, Kamaid A, Thompson JA, Cornwell TL, Radi R, Barbeito L and Beckman JS: Cyclic guanosine 5' monophosphate (GMP) prevents expression of neuronal nitric oxide synthase and apoptosis in motor neurons deprived of trophic factors in rats. Neurosci Lett 326: 201-205, 2002.

23. Wu W, Li L, Yick LW, Chai H, Xie Y, Yang Y, Prevette DM and Oppenheim RW: GDNF and BDNF alter the expression of neuronal NOS, c-Jun, and p75 and prevent motoneuron death following spinal root avulsion in adult rats. J Neurotrauma 20: 603-612, 2003. 
24. Kuno M: Target dependence of motoneuronal survival: the current status. Neurosci Res 9: 155-172, 1990.

25. Keilhoff G, Fansa H and Wolf G: Neuronal NOS deficiency promotes apoptotic cell death of spinal cord neurons after peripheral nerve transection. Nitric Oxide 10: 101-111, 2004.

26. Bredt DS and Snyder SH: Isolation of nitric oxide synthetase, a calmodulin-requiring enzyme. Proc Natl Acad Sci USA 87: 682-685, 1990.

27. Strosznajder $\mathbf{J}$ and Chalimoniuk M: Biphasic enhancement of nitric oxide synthase activity and cGMP level following brain ischemia in gerbils. Acta Neurobiol Exp (Wars) 56: 71-81, 1996.

28. Bradford MM: A rapid and sensitive method for the quantitation of microgram quantities of protein utilizing the principle of protein-dye binding. Anal Biochem 72: 248-254, 1976.

29. Shehab SA and Atkinson ME: Vasoactive intestinal polypeptide (VIP) increases in the spinal cord after peripheral axotomy of the sciatic nerve originate from primary afferent neurons. Brain Res 372: 37-44, 1986.

30. Shehab SA and Atkinson ME: Vasoactive intestinal polypeptide increases in areas of the dorsal horn of the spinal cord from which other neuropeptides are depleted following peripheral axotomy. Exp Brain Res 62: 422-430, 1986.

31. Hokfelt T, Wiesenfeld-Hallin Z, Villar M and Melander T: Increase of galanin-like immunoreactivity in rat dorsal root ganglion cells after peripheral axotomy. Neurosci Lett 83: 217-220, 1987.

32. Villar MJ, Cortes R, Theodorsson E, Wiesenfeld-Hallin Z, Schalling M, Wakisaka S, Kajander KC and Bennett GJ: Effects of peripheral nerve injuries and tissue inflammation on the levels of neuropeptide Y-like immunoreactivity in rat primary afferent neurons. Brain Res 598: 349-352, 1992.

33. Noguchi K, Senba E, Morita Y, Sato M and Tohyama M: Prepro-VIP and preprotachykinin mRNAs in the rat dorsal root ganglion cells following peripheral axotomy. Brain Res Mol Brain Res 6: 327-330, 1989.

34. Noguchi K, De León M, Nahin RL, Senba E and Ruda MA: Quantification of axotomy-induced alteration of neuropeptide mRNAs in dorsal root ganglion neurons with special reference to neuropeptide Y mRNA and the effects of neonatal capsaicin treatment. J Neurosci Res 35: 54-66, 1993.

35. Wakisaka S, Kajander KC and Bennett GJ: Increased neuropeptide Y (NPY)-like immunoreactivity in rat sensory neurons following peripheral axotomy. Neurosci Lett 124: 200-203, 1991

36. Choi Y, Raja SN, Moore LC and Tobin JR: Neuropathic pain in rats is associated with altered nitric oxide synthase activity in neural tissue. J Neurol Sci 138: 14-20, 1996.

37. Yu WH: Nitric oxide synthase in motor neurons after axotomy. J Histochem Cytochem 42: 451-457, 1994.

38. Lindsay RM: Neurotrophins and receptors. Prog Brain Res 103: 3-14, 1994.

39. Hefti F: Pharmacology of neurotrophic factors. Annu Rev Pharmacol Toxicol 37: 239-267, 1997.
40. Terenghi G: Peripheral nerve regeneration and neurotrophic factors. J Anat 194: 1-14, 1999.

41. Schnell L and Schwab ME: Axonal regeneration in the rat spinal cord produced by an antibody against myelin-associated neurite growth inhibitors. Nature 343: 269-272. 1990.

42. Perry VH and Brown MC: Macrophages and nerve regeneration. Curr Opin Neurobiol 2: 679-682, 1992.

43. Griffin JW and Hoffman PN: Degeneration and regeneration in the peripheral nervous system. In: Peripheral Neuropathy. Dyck PJ and Thomas PK (eds). Saunders, Philadelphia, pp361-376, 1993.

44. Clarke D and Richardson P: Peripheral nerve injury. Curr Opin Neurol 7: 415-421, 1994.

45. Rogerio F, Teixeira SA, de Rezende AC, de Sa RC, de Souza Queiroz L, De Nucci G, Muscara MN and Langone F: Superoxide dismutase isoforms 1 and 2 in lumbar spinal cord of neonatal rats after sciatic nerve transection and melatonin treatment. Brain Res Dev Brain Res 154: 217-225, 2005.

46. Wiesenfeld-Hallin Z, Hao JX, Xu XJ and Hokfelt T: Nitric oxide mediates ongoing discharges in dorsal root ganglion cells after peripheral nerve injury. J Neurophysiol 70: 2350-2353, 1993.

47. Koeberle PD and Ball AK: Nitric oxide synthase inhibition delays axonal degeneration and promotes the survival of axotomized retinal ganglion cells. Exp Neurol 158: 366-381, 1999.

48. Thippeswamy T, Jain RK, Mumtaz N and Morris R: Inhibition of neuronal nitric oxide synthase results in neurodegenerative changes in the axotomised dorsal root ganglion neurons: evidence for a neuroprotective role of nitric oxide in vivo. Neurosci Res 40: 37-44, 2001.

49. Watabe K, Ohashi T, Sakamoto T, Kawazoe Y, Takeshima T, Oyanagi K, Inoue K, Eto Y and Kim SU: Rescue of lesioned adult rat spinal motoneurons by adenoviral gene transfer of glial cell line-derived neurotrophic factor. J Neurosci Res 60: 511-519, 2000.

50. Wu W and $\mathrm{Li} \mathrm{L}$ : Inhibition of nitric oxide synthase reduces motoneuron death due to spinal root avulsion. Neurosci Lett 153: 121-124, 1993.

51. Martin LJ, Chen K and Liu Z: Adult motor neuron apoptosis is mediated by nitric oxide and Fas death receptor linked by DNA damage and p53 activation. J Neurosci 25: 6449-6459, 2005.

52. Park CS, Park R and Krishna G: Constitutive expression and structural diversity of inducible isoform of nitric oxide synthase in human tissues. Life Sci 59: 219-225, 1996.

53. Brosnan CF, Battistini L, Raine CS, Dickson DW, Casadevall A and Lee SC: Reactive nitrogen intermediates in human neuropathology: an overview. Dev Neurosci 16: 152-161, 1994.

54. Rogers NE and Ignarro LJ: Constitutive nitric oxide synthase from cerebellum is reversibly inhibited by nitric oxide formed from L-arginine. Biochem Biophys Res Commun 189: 242-249, 1992. 